\title{
A Novel Approach to Incorporate the Main Flux Saturation Effect in a Three-phase Induction Machine during Motoring and Plugging
}

\author{
K. S. Sandhu and Vivek Pahwa
}

\begin{abstract}
In this paper, a new model has been proposed for the transient study of a three phase induction motor, especially for motoring and plugging operation. The ensuing behavior of the machine is predicted by $d-q$ axis based model using MATLAB/SIMULINK environment. Instantaneous value based saturation curve in place of conventional saturation curve has been used to account the saturation in the transient modeling of induction machine. Simulated results as obtained using proposed model are compared with experimental results on the two test machines. A close agreement between the simulated and experimental results proves the validity of proposed modeling.
\end{abstract}

Index Terms-Modeling, Induction motor, Reference frames, Simulation, Transient analysis.

\section{INTRODUCTION}

The three-phase induction machine may results in voltage dips, oscillatory torque and harmonics in the power system during starting period and other severe operations [1]. The estimation of induction motor performance traditionally based on constant parameter models has yielded good engineering results [2]. However it has been observed that some of the machine parameters may not be treated as constant due to saturation in magnetic circuit. Further, it is observed that highly saturated conditions may affect the static and dynamic performance of induction motor drives [3, 4]. For simulation study, different nonlinear models for saturated induction motors have been elaborated based on the equivalent electric circuit approach [5]. An analytical technique [6] has been suggested for predetermination of true saturation characteristic of transformers and reactors from the manufacturer data giving the conventional rms saturation characteristic. The method has some advantages over that suggested by [7]. [8] proposed a new model, in which saturation effects has been incorporated in the magnetizing inductance and the stator mutual inductances. A commercial software package, MATLAB, is used to simulate the dynamic behavior of induction machines with saturable inductances.

The computer results presented in [9] show the errors involved when the magnetizing, stator, and rotor leakage

Manuscript received on December 7, 2010; revised April 5, 2011.

K.S Sandhu is with the Department of Electrical Engineering, National Institute of Technology, Kurukshetra, Haryana, India. (Email: kjssandhu@rediffmail.com).

Vivek Pahwa is with the Department of Electrical and Electronics Engineering, Haryana College of Technology and Management, Kaithal, Haryana,India (Email: pahwa1974@yahoo.com). inductances are assumed constant as in the case of conventional machine model.

The approximate steady state analysis of braking performance of three phase induction motor was given in literature $[10,11]$. [11] has also attempted to identify the transient patterns of torque and currents during plugging, but computed results were not supported by any standard mathematical model. The approach is found to be too approximate to provide proper correlation with experimental results. For transient analysis of three phase induction motor involving asymmetry and/or nonlinearity, the method of instantaneous symmetrical components along with operational equivalent circuits is given in [12-15]. Some of the researchers adopted the finite element modeling for transient study of such machines [16-19]. Same model i.e. finite element model may be adopted for transient study of these machines in plugging mode [20].

Therefore, in order to investigate effect of saturation during motoring and plugging mode in induction machine, the $\mathrm{d}, \mathrm{q}$ axis model has been found to be well tested and proven to be reliable and accurate. [21, 22] also used the $d-q$ axis based conventional model to investigate the transient behavior of three phase induction machine. [23-25] describes the basic concept of transient modeling of the machine. Matlab / Simulink is found to be very useful tool for modeling electrical machine and it may be used to predict the dynamic behavior of the machines. In this paper Matlab / Simulink based new model is proposed to study the dynamic behaviour of three phase induction machine during motoring and as well as in plugging operation.

\section{Mathematical Modeling}

Stationary reference frame model may be adopted to investigate the transient performance of a three-phase induction machine in motoring [25] and plugging. The applied voltages during motoring are:

$$
\begin{gathered}
V_{a s}=V_{m} \cos \left(\omega_{s} t+\lambda\right) \\
V_{b s}=V_{m} \cos \left(\omega_{s} t+\lambda-2 \pi / 3\right) \\
V_{c s}=V_{m} \cos \left(\omega_{s} t+\lambda+2 \pi / 3\right)
\end{gathered}
$$

And, during plugging operation stator voltages are:

$$
\begin{gathered}
V_{a s}=V_{m} \cos \left(\omega_{s} t+\lambda\right) \\
V_{b s}=V_{m} \cos \left(\omega_{s} t+\lambda+2 \pi / 3\right) \\
V_{c s}=V_{m} \cos \left(\omega_{s} t+\lambda-2 \pi / 3\right)
\end{gathered}
$$

According to qdo modeling

$$
\left\lfloor V_{q d o}\right\rfloor=\left\lfloor T_{q d o}\right\rfloor\left[V_{a b c}\right\rfloor
$$


where

$$
\left[T_{q d o}\right]=2 / 3\left[\begin{array}{ccc}
\cos \theta & \cos (\theta-2 \pi / 3) & \cos (\theta+2 \pi / 3) \\
\sin \theta & \sin (\theta-2 \pi / 3) & \sin (\theta+2 \pi / 3) \\
1 / 2 & 1 / 2 & 1 / 2
\end{array}\right]
$$

The voltage balance equation for the $\mathrm{q}$, $\mathrm{d}$ coils in stationary reference frame is as follows (Krishnan, 2007):

$$
[V]=[Z][i]
$$

Where $[V]$ and $[i]$ represents ' $4 \mathrm{x} 1$ ' column matrices of voltage and current and are given as $\left\lfloor V_{q s} V_{d s} V_{q r} V_{d r}\right\rfloor^{T}$ and $\left\lfloor i_{q s} i_{d s} i_{q r} i_{d r}\right\rfloor^{T}$ respectively. And, impedance matrices $(4 \times 4),[Z]$ is given as,

$$
[Z]=\left[\begin{array}{cccc}
R_{s}+L_{s} p & 0 & L_{m} p & 0 \\
0 & R_{s}+L_{s} p & 0 & L_{m} p \\
L_{m} p & -\omega_{r} L_{m} & R_{r}+L_{r} p & -\omega_{r} L_{r} \\
\omega_{r} L_{m} & L_{m} p & \omega_{r} L_{r} & R_{r}+L_{r} p
\end{array}\right]
$$

\section{Incorporation of instantaneous value based saturation curve}

The non-linear relation between magnetizing reactance, ' $\mathrm{X}_{\mathrm{m}}$ ' and magnetizing current, ' $\mathrm{I}_{\mathrm{m}}$ ' of two machines (Appendix-I),using conventional modeling may be represented as;

$$
\begin{aligned}
& \mathrm{X}_{\mathrm{m}}=-1.225 \mathrm{I}_{\mathrm{m}}^{3}+22.293 \mathrm{I}_{\mathrm{m}}^{2}-128.027 \mathrm{I}_{\mathrm{m}}+294.936 \Omega \\
& \mathrm{X}_{\mathrm{m}}=0.3372 \mathrm{I}^{3}{ }_{\mathrm{m}}-1.8650 \mathrm{I}_{\mathrm{m}}^{2}+9.1425 \mathrm{I}_{\mathrm{m}}+114.2482 \Omega
\end{aligned}
$$

Saturation curve as defined below may be modified (Appendix-I) and represented respectively as:

$$
\begin{gathered}
\mathrm{x}_{\mathrm{m}}=0.755 \mathrm{i}^{3}{ }_{\mathrm{m}}-7.703 \mathrm{i}_{\mathrm{m}}^{2}-4.8319 \mathrm{i}_{\mathrm{m}}+196.78 \quad \Omega \\
\mathrm{x}_{\mathrm{m}}=0.1205 \mathrm{i}^{3}{ }_{\mathrm{m}}-0.7154 \mathrm{i}^{2}{ }_{\mathrm{m}}+8.6888 \mathrm{i}_{\mathrm{m}}+114.4563 \Omega(7)
\end{gathered}
$$

The above modified relationships may be adopted to account the saturation effect during the transient study of a three-phase induction machine.

The magnetizing current, ${ }^{i}$ is defined as:

$$
i_{m}=\sqrt{i_{d t}^{2}+i_{q t}^{2}}
$$

and

$$
\begin{gathered}
i_{d t}=i_{d s}^{r}+i_{d r}^{r} \\
i_{q t}=i_{q s}^{r}+i_{q r}^{r}
\end{gathered}
$$

\section{Equation of Motion}

Expression for electromagnetic torque using d-q axis model is given as,

$$
T_{e}=\frac{3}{2} \frac{P}{2} L_{m}\left(i_{q s}^{r} i_{d r}^{r}-i_{d s}^{r} i_{q r}^{r}\right) \quad \text { (N.m) }
$$

Whereas, the equation of motion may be defined as,

$$
\mathrm{T}_{\mathrm{e}}-\mathrm{T}_{\mathrm{L}}=-2 \mathrm{H}\left(\mathrm{P} \omega_{\mathrm{r}} / \omega_{\mathrm{b}}\right)-\mathrm{T}_{\mathrm{damp}}
$$

Where inertia constant ' $\mathrm{H}$ ', is defined as the ratio of the kinetic energy at base speed to the rated power and $\mathrm{T}_{\text {damp }}$, is damping torque.

\section{RESUlts AND Discussions}

Figure 1-2 shows the comparison of simulated results (using conventional and proposed model) with experimental results on two test machines $1 \& 2$ [Appendix-II]. The machines under consideration initially run at no-load in motoring mode. After one second operation is changed to plugging mode by reversing the phase sequence of the supply system. Figure 1 shows the variation of stator phase currents with time. Analysis of figure1 and figure2 gives the following observations;

i. Simulated results as obtained using proposed model are close to experimental results. This proves the effectiveness of proposed modeling in contrast to conventional modeling and hence the same may be used to investigate the transient performance of induction machines.

ii. Inrush current drawn from the supply system becomes even greater than motoring mode during the change of operation from motoring to plugging mode. This necessitates a strong need to control this current during change over period.

iii. For the same machines settling time for plugging operation is found to be more as compared to its operation in motoring mode.

Simulated results of voltage, instantaneous value of current, torque, rotor speed and magnetizing current of machine-2, have been shown in figures 3,4 and figures 5, 6 without and with moment of inertia of the system attached respectively. Analysis of these figures gives the following observations;

i. Proposed transient modeling results into a large value of magnetizing current in contrast to conventional transient modeling for three phase induction machine. Hence in the absence of any starting arrangement, there is a possibility of saturation in magnetic circuit of the machine.

ii. There is hardly any appreciable change in the variation of torque and speed with time.

Figure 7 and 8 shows the variation of instantaneous torque of the machine with conventional and proposed modeling.

i. The rotor speed overshoots and the torque speed curve shows decayed oscillations about the final operating point during motoring and plugging mode (refer figure7).

ii. Figure 8 shows the effects of an increase in moment of inertia. It is found that transients appear initially during motoring and plugging, the rotor speed is highly damped and the final operating point is attained without oscillations. The large transient mechanical stresses on the motor shaft can be seen very high during plugging mode instead of motoring mode.

iii. Another noticeable point, in the torque speed characteristics incorporating conventional and proposed model, is that the simulated value of torque during changeover process is more with conventional model i.e. with conventional saturation curve. 

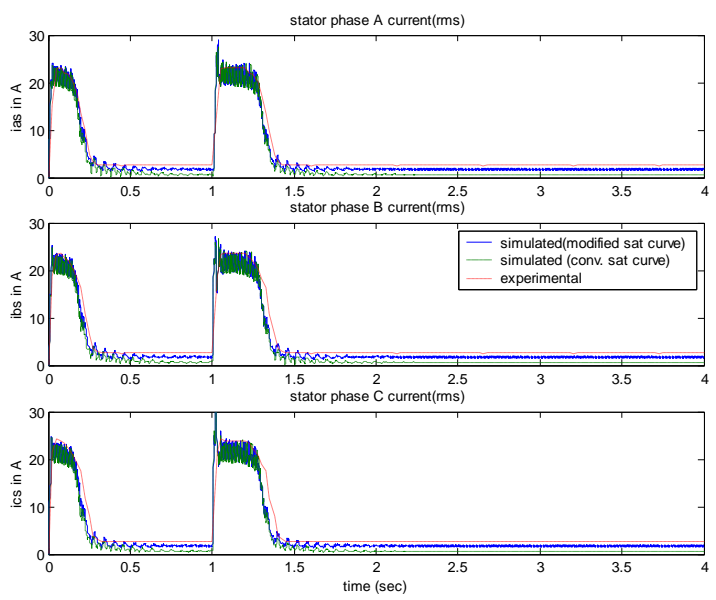

Fig.1: Transient phase currents for machine-1, $\mathrm{J}=0.23 \mathrm{kgm}^{2}$.
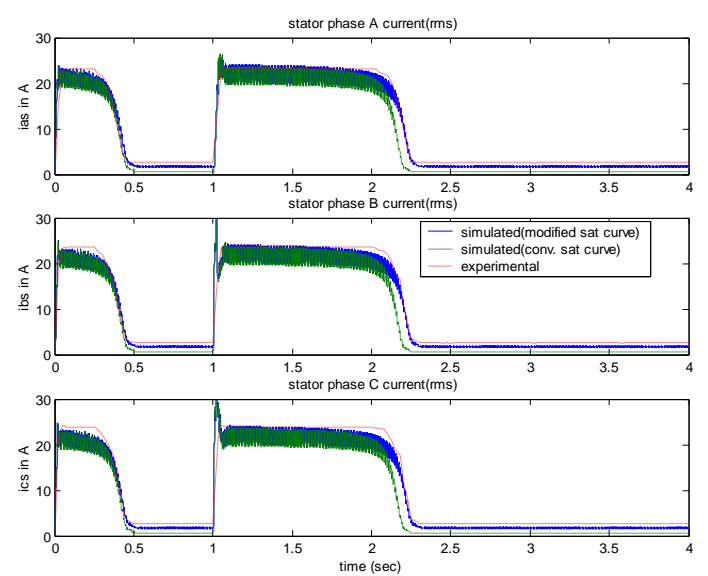

Fig.2: Transient phase currents for machine-2, $\mathrm{J}=0.913 \mathrm{kgm}^{2}$.
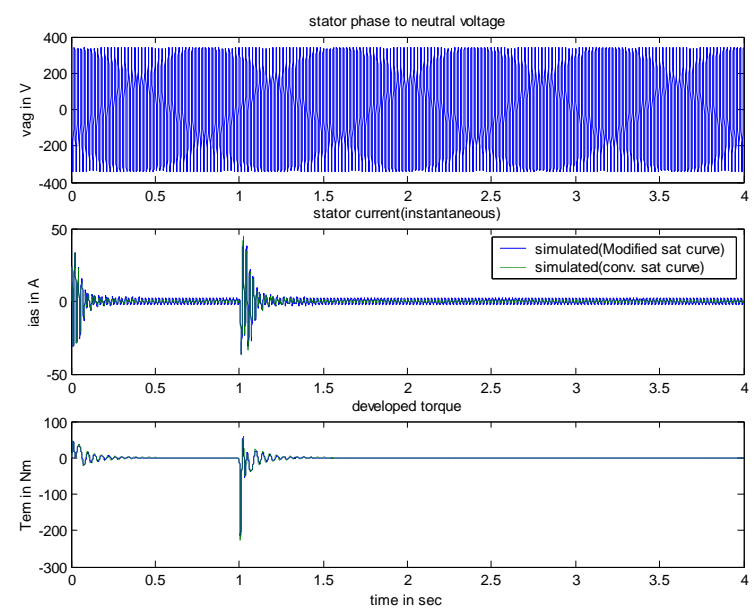

Fig.3: Simulated transient results for voltage, current and torque for machine- $2, \mathrm{~J}=0.113 \mathrm{kgm}^{2}$.
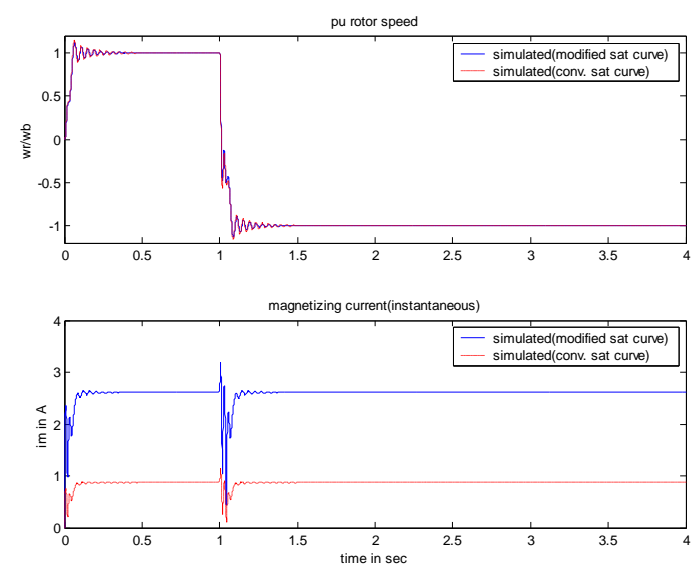

Fig.4: Simulated transient results for rotor speed and magnetizing current for machine- $2, \mathrm{~J}=0.113 \mathrm{kgm}^{2}$.
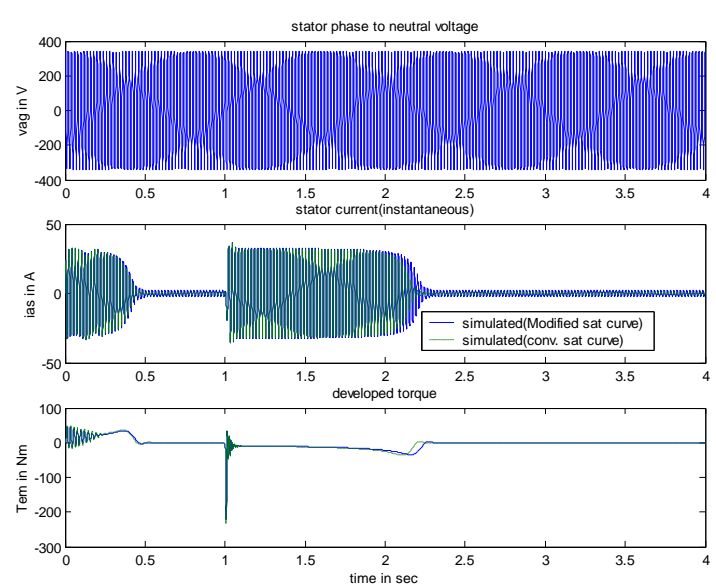

Fig.5: Simulated transient results for voltage, current and torque for machine- $2, \mathrm{~J}=0.913 \mathrm{kgm}^{2}$.
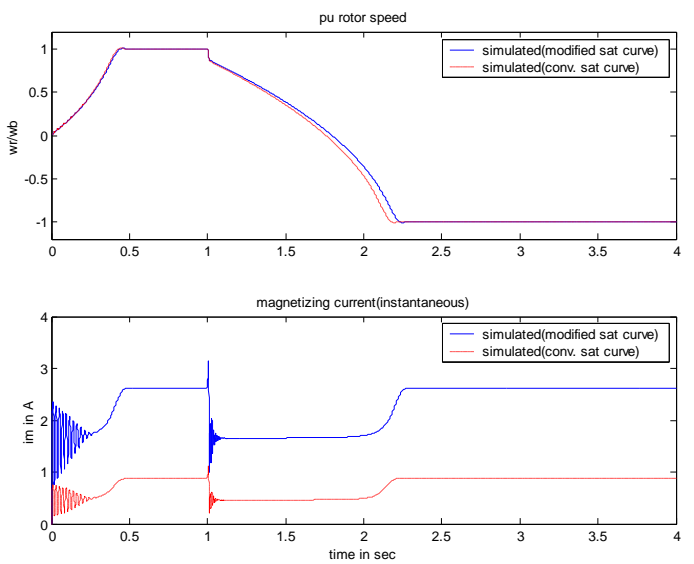

Fig.6: Simulated transient results for speed and magnetizing current for machine- $2, \mathrm{~J}=0.913 \mathrm{kgm}^{2}$ 


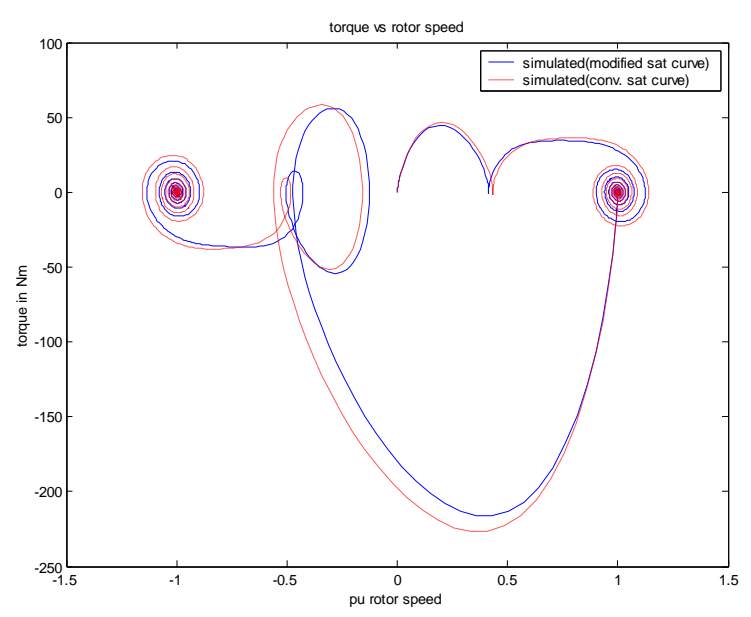

Fig.7: Simulated transient results of torque- speed characteristics for machine- $2, \mathrm{~J}=0.113 \mathrm{kgm}^{2}$.

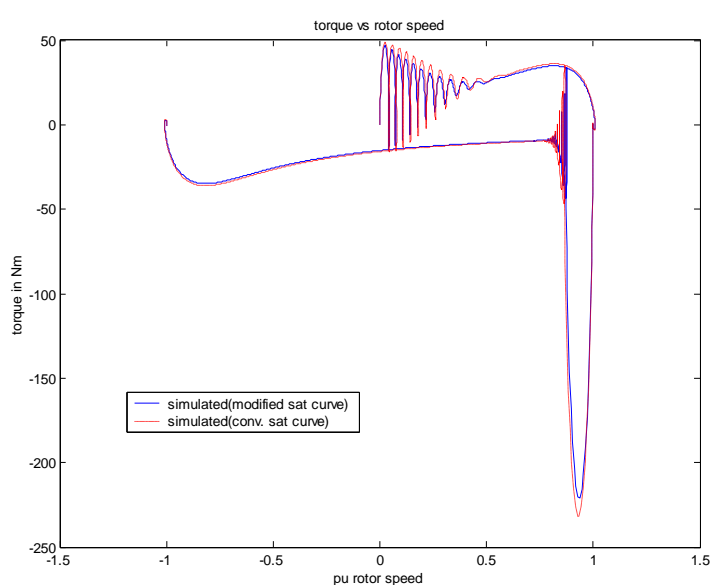

Fig.8: Simulated transient results of torque- speed characteristics for machine- $2, \mathrm{~J}=0.913 \mathrm{kgm}^{2}$

\section{CONCLUSION}

In this paper, an attempt is made to analyze the dynamic behaviour of three phase induction machine using a new proposed model, which incorporates the saturation effect in a different manner in contrast to conventional models. A close comparison of simulated results using proposed modeling on two test machines with experimental data, confirms the validity and superiority of proposed model. Simulated results as obtained are further used to describe the dynamic behaviour of three phase induction machine in motoring and plugging operation.

\section{APPENDIX}

\section{Appendix-I}

The 3-phase induction motor under consideration is driven at rated synchronous speed with prime mover, after ensuring that the two machines run in the same direction if fed individually. Input current, power is recorded for different values of applied voltage. As shown in figure 9 and figure 10, observations as obtained may be used to plot the r.m.s. value based saturation curve of induction machine. The data as obtained may be further used to develop the instantaneous value based saturation curve and it is shown in figure 11 and figure 12:

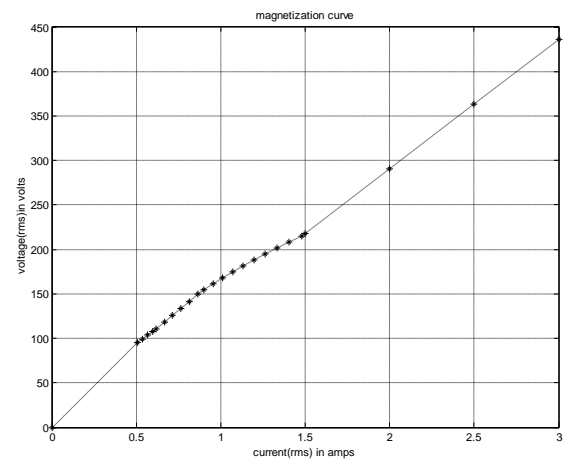

Fig.9: Saturation curve of machine1.

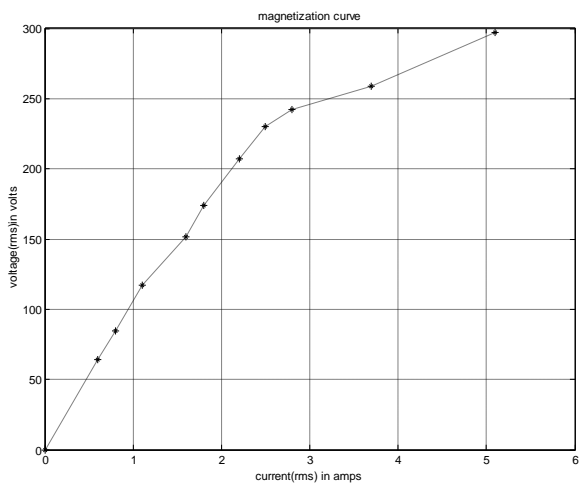

Fig.10: Saturation curve of machine2.

Modeling as given below may be used to convert conventional saturation curve into modified saturation curve. For a sinusoidal input voltage of frequency, $\omega$, the corresponding flux linkage is given by

$\Psi_{k}=\sqrt{2} V_{k}, \mathrm{k}=0,1$,

Instantaneous value of current is obtained as

$i_{k}=\sum_{j=1}^{k} K_{j}\left(\Psi_{j}-\Psi_{j-1}\right), \mathrm{k}=0,1,---------, \mathrm{n}$

Where; $K_{j}$ is the inverse of slope of line joining two points $j \&(j-l)$ on the curve and ' $n$ ' is total number of points on the curve under consideration $\&$ in this paper its value is fifteen.

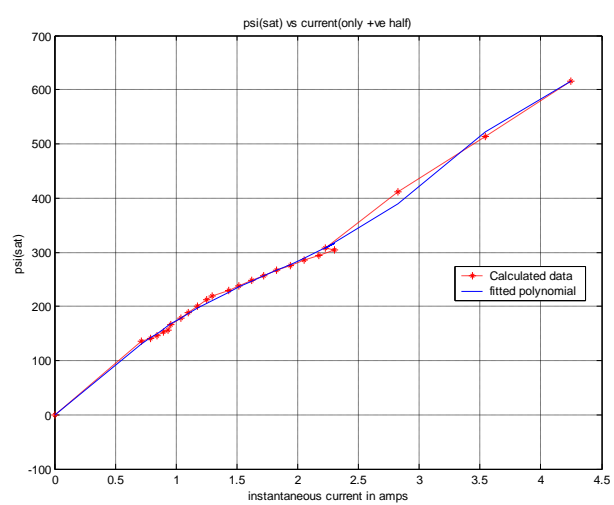

Fig.11: Modified saturation curve of machine1. 


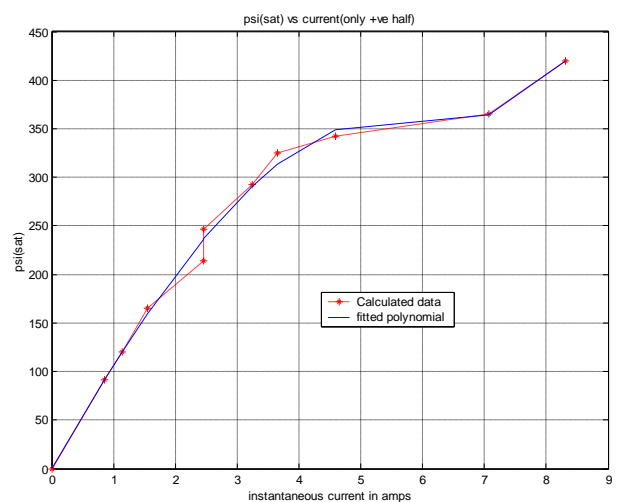

Fig.12: Modified saturation curve of machine2.

Appendix-II

Machine-1

3-hp, 3-phase, $50 \mathrm{~Hz}, 415$ volts Induction Motor;

Stator Resistance, $\quad \mathrm{R}_{\mathrm{s}}=4.44 \mathrm{ohms}$

Rotor Resistance, $\quad \mathrm{R}_{\mathrm{r}} \quad=0.9512 \mathrm{ohms}$

Stator \& Rotor Inductance, $\quad \mathrm{L}_{\mathrm{s}}=\mathrm{L}_{\mathrm{r}}=14.97 \mathrm{mH}$

Moment of Inertia of test machine set up

Without coupling, $\mathrm{J}=0.113 \mathrm{kgm}^{2}$

Moment of Inertia of test machine set up

With coupling, J $\quad=0.23 \mathrm{kgm}^{2}$

Machine-2

3-hp, 3-phase, $50 \mathrm{~Hz}, 220$ volts Induction Motor;

Stator Resistance, $\quad \mathrm{R}_{\mathrm{s}}=3.35 \mathrm{ohms}$

Rotor Resistance, $\quad \mathrm{R}_{\mathrm{r}} \quad=1.7 \mathrm{ohms}$

Stator \& Rotor Inductance, $\quad \mathrm{L}_{\mathrm{s}}=\mathrm{L}_{\mathrm{r}}=15.44 \mathrm{mH}$

Moment of Inertia of test machine set up

Without coupling, J $=0.113 \mathrm{kgm}^{2}$

Moment of Inertia of test machine set up

With coupling, J $\quad=0.913 \mathrm{kgm}^{2}$

\section{NOMENCLATURE}

$V_{a s}, V_{b s}, V_{c s}=$ Bus bar voltages for phase $\mathrm{A}, \mathrm{B}$ and $\mathrm{C}$ respectively

$V_{m}=$ Maximum Voltage

$V q d s=$ Stator $\mathrm{q}$ and $\mathrm{d}$ axes voltages in stationary reference frame

$V q d r=$ Rotor $\mathrm{q}$ and $\mathrm{d}$ axes voltages in stationary reference frame

iqds = Stator $\mathrm{q}$ and $\mathrm{d}$ axes currents in stationary reference frame

iqdr $=$ Stator $\mathrm{q}$ and $\mathrm{d}$ axes voltages in stationary reference frame

$R_{s} \quad=\quad$ Stator Phase Resistance/phase

$L_{s} \quad=\quad$ Stator Self inductance/phase

$L_{m} \quad=\quad$ Mutual inductance/phase

$R_{r} \quad=\quad$ Rotor Phase Resistance/phase

$L_{r} \quad=\quad$ Rotor self inductance/phase $\omega_{s}=$ Angular speed (radian $/ \mathrm{sec}$.) in synchronously rotating reference frame

$J \quad=\quad$ Inertia of Motor

$T_{e} \quad=\quad$ Electrical Torque

$T_{L} \quad=\quad$ Load Torque

$p=$ Operator for differentiation

$\lambda=$ Initial angle in degrees

Subscripts:

d

0

$\mathrm{s}$

r

$\begin{array}{ll}= & \text { Quadrature axis } \\ = & \text { Direct axis } \\ = & \text { Zero axis } \\ = & \text { Stator quantities } \\ = & \text { Rotor quantities }\end{array}$

$=$ Rotor quantities

\section{REFERENCES}

[1] P. C. Krause and C. H. Thomas, "Simulation of symmetrical induction machinery," IEEE Transactions on Power Apparatus and Systems, PAS-84, pp. 1038-1053, 1965.

[2] F. P. De Mello and G. W. Walsh, "Reclosing Transients in Induction Motors with Terminal capacitors," IEEE Transactions on Power Apparatus and System, PAS-80, pp. 1206-1213, 1961.

[3] R.D. Lorenz and D.W. Novotny," Saturation Effects in Field-Oriented Induction Machines," IEEE Transactions on Industry Applications, Vol.26, No. 2, pp. 283-289, 1990.

[4] F. Khater, R.D. Lorenz and D.W. Novotny," Selection of Flux Level in Field-Oriented Induction Machine Controller with Consideration of Magnetic Saturation Effect," IEEE Transactions on Industry Applications, Vol.23, No. 2, pp. 276-282, 1984

[5] J.C. Moreira and T.A. Lipo, "Modeling of Saturated AC Machines Including Air Gap Flux Harmonic Components," IEEE Transactions on Industry Applications, Vol. 28, No.2, pp. 343- 349, 1992.

[6] S. Prusty and M.V.S. Rao," A Direct Piecewise Linearized Approach to Convert rms Saturation Characteristics to instantaneous Saturation Curve," IEEE Transactions on Magnetics, Vol 16, No.1, pp. 156-160, 1980 .

[7] S. N. Talukdar, J.K.Dickson, R.C.Dugan, M.J.Sprinzen and C.J.Lenda,"On modeling transformers and reactor saturation characteristics for digital and analog studies," IEEE Transactions on Power Apparatus and Systems, PAS-94, No. 2, pp. 612-621, 1975.

[8] V. Donescu, A. Charette, Z. Yao and V. Rajagopalan," Modeling and Simulation of Induction Motors in Phase Quantities," IEEE Transactions on Energy Conversion, Vol. 14, No. 3, pp: 386-392, 1999.

[9] O. I. Okoro," MATLAB Simulation of induction Machine with Saturable leakage and Magnetizing Inductances," The Pacific Journal of Science and Technology, Vo1.5,No.1, pp. 5-15, 2003.

[10] P.V. Volotsenko and A. M. Meisel et al," Braking Asynchronous Motors with Simultaneous A.C. and D.C Currents," Journal of Machines and Tooling, Vol. XXXV, No. 9, pp: 17 -20, 1964.

[11] E.A. McGennis ," A Noval Braking Scheme for Induction Machines. IEEE Transactions on Power Apparatus and Systems, "Vo1. 90, No. 6 , pp. 2610-2615, 1971 .

[12] S.S. Murthy, Bhim Singh and A.K. Tondon," Dynamic Model for Transient Analysis of Induction Machines with Asymmetrical Winding Connections," Electric Machines and Electromechanics, Vo1. 6, No. 6 pp. 479-492, 1981.

[13] S.S. Murthy and G. J. Berg," A New Approach to Dynamic Modeling and Transient Analysis of SCR-Controlled Induction Motors. IEEE Transactions on Power Apparatus and Systems," Vo1. PAS -101, No. 9, pp: 3141- 3150, 1982.

[14] Murthy , S.S., G. J. Berg, Bhim Singh, C.S. Jha and B.P. Singh Transient Analysis of a 3-Phase Induction Motor with Single Phase Supply. IEEE Transactions on Power Apparatus and Systems, Vo1. PAS -102, No. 1, pp. 28-37, 1983.

[15] J.R.P. Gupta, Bhim Singh and B.P. Singh," Transient Analysis of Solid State Plug Braking of Induction Motors," IEEE Transactions on Industry Applications, Vol. 24, No. 5, pp. 758-764, 1989. 
[16] S. R. H. Hoole," Rotor motion in the dynamic finite element analysis of rotating electrical machinery," IEEE Transactions on Magnetics, Vol. 21, pp. 393-400, 1985.

[17] M. Ito, N. Fujimoto, H. Okuda, N. Takahashi and T. Miyata," Analytical model for magnetic field analysis of Induction Motor performance," IEEE Transactions on Power Apparatus and Systems, Vol.100, pp. 405-414, 1981.

[18] Williamson, S. and J. W. Ralph, 1983. Finite element analysis of Induction Motor Fed from a constant voltage source. IEE Proceeding on Electric Power Applications, Vol. 130, pp: 88-94.

[19] E. Vassent , A. Meunier, A. Foggia and J. C. Sabonnadiere," Simulation of Induction machine operation using a step- by-step finite element method," Journal of Applied Physics, Vol. 67, pp: 5807-5811, 1990.

[20] C.B. Rajanathan, Zhan W. Shi and David S. Thompson," Electromechanical Transient in a Three-Phase Induction Motor during Phase Failure and Plugging," IEEE Transactions on Magnetics, Vol. 33 No. 2, pp. 1219-1222, 1997.

[21] S. Ertem and Y. Baghzouz," Simulation of Induction Machinery for Power System Studies," IEEE Transactions on Energy Conversion, Vol.4, No. 1, pp. 88-94, 1989.

[22] Improved Model for the Simulation of Deep Bar Induction Motor. IEEE Transactions on Energy Conversion, Vol. 5, No. 2, pp: 393-400.

[23] Krause, Paul C., O. Wasynczuk and S. D. Sudhoff, 2004. Analysis of Electric Machinery and Drive systems. IEEE Press Series on Power Engineering, John Wiley \& Sons Inc. Publication.

[24] Bose, B. K., 2007. Power Electronics and AC Drives, Pearson Prentice Hall.

[25] Krishnan, R., 2007. Electric Motor Drives. Pearson Prentice Hall.

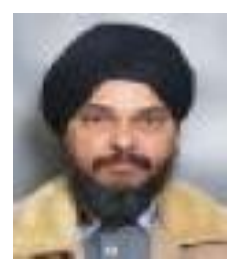

Dr. K.S. Sandhu was born at Sewan, Haryana, India in 1957. He received the B.Sc. Engg. (Electrical), M. Sc. (Electrical) and $\mathrm{PhD}$ (Electrical Machines) degrees from Regional Engineering College, Kurukshetra University, Kurukshetra, India in 1981, 1985 and 2001 respectively. He joined the Electrical Engineering Department of Regional Engineering College, Kurukshetra, as Lecturer in January 1983. Currently, he is Professor and Head of Electrical Engineering Department, National Institute of Technology, Kurukshetra India. His areas of interest include electrical machines, drives, power system, induction generators, wind energy conversion, power quality, energy management, distributed generation an application of artificial intelligence. He has more than ninety publications in reputed journals and conference proceedings. He has supervised successfully two $\mathrm{PhD}$ candidates and presently eight $\mathrm{PhD}$ research scholars are working under his supervision in above mentioned areas.

B. Author: Mr. Vivek Pahwa was born at Kaithal, Haryana, India in 1974. He received the B.E. and M. Tech. Degree in Electrical Engineering from R.E.C., Kururkshetra, Kurukshetra University, Kurukshetra, Haryana, India and NIT, Kurukshetra in 1997 and 2005, respectively. He is pursuing his received his $\mathrm{PhD}$ degree in Electrical Engineering from NIT, Kurukshetra, Haryana, India. $\mathrm{He}$ is working in the Department of Electrical and Electronics Engineering as an associate professor at Haryana College of Technology and Management, Kaithal, Haryana, India.

Email: pahwa1974@yahoo.com 